\title{
TRADUCTOR DE TEATRO / TRADUCTOR EN EL TEATRO. ENTRE NOSOTROS, TODO VA BIEN DE DOROTA MASŁOWSKA EN EL ESCENARIO ESPAÑOL
}

\begin{abstract}
Resumen. El artículo plantea preguntas sobre los múltiples papeles del traductor teatral. Después de presentar los temas básicos de la traducción teatral, se discuten sus dos formas principales: la traducción literaria y la traducción escénica. Dentro de esta última se distinguen: audiodescripción, lenguaje de señas, resumen escrito, resumen oral, paráfrasis, interpretación simultánea y subtítulos. La parte práctica del artículo se centra en el análisis de la versión teatral de Grzegorz Jarzyna (presentación preliminar: 26 de marzo de 2009, Schaubühne am Lehniner Platz, Berlín) de la pieza teatral de Dorota Masłowska Między nami dobrze jest (2008, Warszawa, Lampa i Iskra Boża) y su traducción en forma de sobretítulos en español titulada Entre nosotros, todo va bien de Xavier Farré (estreno: 4 de noviembre de 2011, Teatro Valle-Inclán, Madrid).
\end{abstract}

Palabras clave: traducción para la escena, traductor de teatro, sobretítulos, Dorota Masłowska, Entre nosotros, todo va bien.

\section{Pequeña introducción}

El artículo parte de la pregunta sobre los papeles del traductor en el ambiente escénico. Se ponen a discusión los siguientes aspectos: la traducción teatral para el libro y para la escena. Este último subdividido en la traducción escénica tradicional, la audiodescripción, la lengua de signos, el resumen escrito, el resumen oral, el parafraseo, la interpretación simultánea y los subtítulos. La parte práctica del texto se centra en la versión teatral de Grzegorz Jarzyna (preestreno el 26 de marzo de 2009, Schaubühne am Lehniner Platz, Berlín) de la pieza polaca Między nami dobrze jest de Dorota Masłowska (2008, Warszawa, Lampa i Iskra Boża) y su traducción al español, en forma de sobretítulos, titulada como Entre nosotros, todo va bien realizada por Xavier Farré, presentada en la escena

\footnotetext{
* Uniwersytet Łódzki.
} 
madrileña en el Teatro Valle-Inclán en 2011 (estreno el 4 de noviembre). En nuestro análisis nos enfocaremos en la especificidad de este tipo de traducción -sobretítulos- y a su vez en el marco de este, la traducción de las referencias culturales polacas al español: la cultura material, institucional y mental. Reflexionaremos sobre el papel del traductor como mediador intercultural en el medio de la traducción escénica.

\section{Traducción teatral. Ideas generales}

En primer lugar, subrayemos que hay muy pocos libros y artículos que de forma integral o sumaria traten el tema del texto dramático y su traducción. Generalmente los estudios sobre la traducción dramática se encuadran dentro de los estudios de la traducción literaria o presentan aspectos puntuales de la traducción dramática (Ezpeleta Piorno, 2007: 139).

En segundo lugar, hay que acentuar la constante dualidad que presenta el texto dramático, así como su dicotomía o doble naturaleza, ya que este sirve tanto para ser leído, como para ser representado, hecho que sin duda influye profundamente en el trabajo traductológico. Por ello, para abordar este proceso de manera eficaz debemos toparnos (necesariamente) con dos teorías: la teoría literal del drama y la teoría teatral del drama.

Los investigadores polacos, Roman Ingarden, Maria R. Mayenowa y Konrad Górski, quienes desarrollaron la teoría literaria del drama, afirman que una obra dramática es una parte integral de la literatura y que esta no es idéntica a la escenificación teatral. Sustentan esta concepción sobre el hecho de que no existe una sola escenificación, sino una multiplicidad de ellas, junto a sus respectivas lecturas. Sin embargo, por regla general, estas están o deben estar de acuerdo con las intenciones del autor, quedando fiel a la figura de este mismo. Hay autores extranjeros como, por ejemplo, Jiri Veltrusky, que también sustentan esta teoría considerando el drama como un género literario, argumentando, a su vez, que la puesta en escena queda fuera de sus límites genéricos, y que debería ser trabajada solamente por la gente del teatro, es decir, por los directores y actores.

Enlosañoscuarenta, enPolonia, la teoría teatral deldrama representada sobre todo por Stefania Skwarczyńska y Zbigniew Raszewski, veía el teatro como una partitura que consistía no solo en la reproducción de los textos, sino también en la descripción del espacio, la estructura del tiempo dramático y el desarrollo técnico-escénico del actor (entonación, mímica, 
gesticulación, movimiento escénico) que llega a su plena realización en la escena, siendo un elemento más del arte dramático-teatral.

Por otro lado, hay críticos, como Anne Ubersfeld, Susan Bassnett, Manuel A. Conejero, Robert W. Corrigan, etc., que postulan la imposibilidad de separar el texto de su representación, subrayando una relación dialéctica entre ambos. Todo esto nos lleva a la llamada paradoja del traductor, ya que «se le pide que trate un texto escrito, que es solo una parte de un sistema de signos mucho más amplio y complejo que incluye aspectos paralingüísticos, relacionados con el gesto y el movimiento, etc., como si se tratase de un texto literario creado solamente para su lectura» (Ezpeleta Piorno, 2007: 147).

\section{Tipos de traductores / traducciones teatrales}

Hay traductores de teatro que no están relacionados con el medio teatral, por el contrario, los hay que son empresarios teatrales, directores o actores, que quieren integrar en su repertorio los textos clásicos o novedades extranjeras del mundo teatral. Unos crean la traducción de forma autónoma, mientras que otros colaboran con la gente de teatro y a menudo asisten al trabajo de mesa conformando así parte del proceso creador del drama, entendido este último como el proceso de análisis del texto, análisis literario, alrededor de la mesa (de allí su nombre), siendo este uno de los métodos para preparar la representación del espectáculo teatral. Este proceso plantea un fuerte contraste con el análisis teatral, que solo puede ser llevado a cabo en el escenario mismo, actuando. Por otro lado, hay algunas traducciones teatrales creadas para un director en concreto o para la realización de una pieza teatral específica, hecho por el cual, a menudo unos directores con un traductor forman algunos tándems de escenificación. Muchos traductores participan de forma activa en el proceso de la creación de la representación, cumpliendo los siguientes papeles: ayudar al director durante los ensayos como consultores, como dramaturgos, como adaptadores; escribir los textos, editar los programas educativos que acompañan a los estrenos, organizar encuentros y festivales. Algunos incluso son curadores y networkers, de esta forma inician el transfer intercultural (Blikont et al., 2014: 130). A continuación nos acercaremos a diversas formas de traducción teatral.

Dentro de los diferentes tipos de traducción del teatro, enumeraremos sobre todo las dos principales, a saber, la traducción teatral textual y la 
traducción escénica. La primera se fija antes que nada en la palabra, en los monólogos y diálogos, en su expresión natural y auténtica, menos en los rasgos paralingüísticos, quedándose al lado del texto original. Frente a esta, la segunda, la escénica, se enfoca de la misma manera en los elementos lingüísticos y paralingüísticos, concentrándose en la oralidad del texto y la inmediatez de su recepción, por lo que queda al lado del texto meta. En ocasiones encontramos ambas ediciones de una obra, una para la lectura y otra para la escena. Ahora nos adentraremos en diferentes subtipos de la traducción escénica, a saber, la audiodescripción, la lengua de signos, el resumen escrito, el resumen oral, el parafraseo, la interpretación simultánea y los subtítulos.

La audiodescripción (AD) es la descripción verbal en directo de la acción de la obra teatral, que incluye también descripciones de vestuario, ambientación, iluminación y de actores (expresiones faciales, gestos, movimientos corporales), esta se lleva a cabo para las personas con problemas de visión: invidentes totales o personas con dificultades visuales. La realizan los descriptores entrenados que se sientan en un área insonorizada, por ejemplo, en la cabina de sonido, y los espectadores a su vez la oyen a través de los auriculares. Se diferencia la audiodescripción intra e interlingüística (Gambier, 2004: 3-4).

Las primeras audiodescripciones en el teatro aparecen a través de la radio en los años 40, siendo retransmitidas desde los teatros, por ejemplo, desde el Gran Teatre del Liceu de Barcelona. La traducción era del mismo descriptor. El precursor de la transmisión en España fue Radio Nacional de Barcelona. La primera audiodescripción en directo en el mundo tuvo lugar en el teatro Arena Stage en Washington en el año 1981, gracias a Margaret Rockwell y Cody Pfanstiehl. Mientras que la primera AD en directo en Cataluña tuvo lugar en 1994 y desde 2004 suele ser usada regularmente, por ejemplo, en el Gran Teatre del Liceu de Barcelona.

También existe una introducción a la $\mathrm{AD}$. Se trata de segmentos de 5 a 15 minutos realizados antes de la representación de la pieza, que contiene el resumen de la trama, entrevistas con el elenco y el director, información importante del programa y descripciones detalladas de decoración y trajes.

La interpretación dramatizada en la lengua de signos la realiza el intérprete en directo durante la pieza. Se puede interpretar a la lengua de signos todas las actividades didácticas y lúdicas que acompañan a la obra teatral. El intérprete se encuentra en la escena, en el medio, al costado, etc., dependiendo de la pieza, y traduce todos los parlamentos de los actores y los sonidos que no se pueden ver. No hay una lengua de signos universal, mundial, sino varias que no siempre compaginan con las 
lenguas habladas. En Polonia existen dos tipos de comunicación manual: la lengua de signos polaca (PJM) y el sistema lingüístico-gestual polaco (SJM). En España hay una lengua de signos españoles o lengua de señas españolas (LSE).

El resumen escrito se utilizaba en el teatro sobre todo hasta los años noventa del siglo XX; enumeremos como ejemplo la ópera Die Zauberflöte de Wolfgang Amadeus Mozart representada en los años 1990-1991 en el Gran Teatre del Liceu de Barcelona. El resumen escrito a principio de los años noventa fue reemplazado por la subtitulación.

Jennifer Lindsay (2007: 141, 255) en su libro titulado Between Tongues: Translation And / of / in Performance in Asia enumera tres tipos de traducciones sobre la escena practicados en el continente asiático, a saber, el resumen oral y el parafraseo, ambos usados en la khon performance para presentar en el tailandés contemporáneo lo que era presentado en las lenguas clásicas; y la traducción semi-simultánea durante el teatro de títeres javaneses, wayang kulit.

La subtitulación electrónica consiste en la proyección de subtítulos a través de un proyector independiente que lanza los subtítulos simultáneamente con la acción que tiene lugar en el escenario. A menudo está presente un técnico que es responsable de la sincronización de los subtítulos con las voces de los actores. Hay subtítulos en lenguas extranjeras, pero también para los sordos e hipoacúsicos. En el segundo caso, los subtítulos contendrán también informaciones sobre los sonidos y la música, necesarias para la comprensión y la recepción adecuadas de la obra teatral. Después de la preparación de los subtítulos, estos serán emitidos durante la obra en directo, y la persona que proyectará los subtítulos, a menudo el traductor, tendrá que saber reaccionar a los cambios en el texto, ya que cada espectáculo es un poco diferente: puede haber pausas en puntos diferentes, el orden del texto cambia, puede faltar algún fragmento de parlamento, y hay que contar con la improvisación de los actores.

También se usan los subtítulos en varias lenguas que aparecen en pantallas de cristal líquido situadas en la parte trasera de las butacas. Asimismo hay un dispositivo de mano llamado AirScript, un traductor electrónico personal que durante la pieza teatral traduce los parlamentos de los actores a ocho lenguas: inglés, español, italiano, francés, alemán, ruso, japonés o chino. Las traducciones hechas por los traductores profesionales aparecen en tiempo real, gracias a la señal que recibe el aparato por la red inalámbrica. El fondo de la pantalla es negro, mientras los subtítulos son naranjas, lo que disminuye la luz emitida. El primer 
teatro que dispuso de esa tecnología fue el Teatro Shaftesbury en Londres, en noviembre de 2009 durante el musical Hairspray (BBC, 2009).

Yves Gambier en «La traduction audiovisuelle: un genre en expansion» de 2004 distingue doce modos de traducción audiovisual, entre los que enumera los subtítulos. Los subtítulos en la ópera o en el teatro se sitúan encima del escenario o detrás de la butaca y se proyectan en directo; pueden ser la traducción literal del libreto o pieza teatral, o depender de la escenificación que se lleva a cabo. De esta forma su traducción se crea cada vez durante la realización de una actuación (Gambier, 2004: 3). A su vez Teresa Tomaszkiewicz (2006) en Przekład audiowizualny (Traducción audiovisual), junto a los tres principales tipos de TAV -el doblaje, los subtítulos y las voces superpuestas- enumera tipos secundarios, entre los cuales se encuentran los sobretítulos en la ópera y subtítulos para los sordos (2006: 121-123).

Los sobretítulos son los subtítulos que se proyectan o se emiten durante la representación en el teatro o en la ópera. Se muestran en una pantalla situada encima del escenario, casi siempre en la parte superior de la boca del mismo. Los sobretítulos se usaron por primera vez en la Canadian Opera Company (COC) el 21 de enero de 1983 durante la pieza Electra de Richard Strauss. El inventor de los sobretítulos fue John Leberg, director operativo de COC. En los años ochenta se usaban máquinas de escribir y diapositivas, y más tarde los proyectores de texto computarizados (Eatock, 2003).

Los sobretítulos se usan en los teatros más importantes de España, sobre todo durante los festivales teatrales internacionales. También estos son frecuentes en las comunidades autónomas, en las que el castellano se subtitula con otras lenguas cooficiales de la Península Ibérica (Carrillo Darancet, 2014: 57-58). Carrillo Darancet describe el sobretitulado de la siguiente forma: «la presentación necesariamente condensada de la traducción de una obra en dos líneas con un máximo de hasta 40 caracteres por línea en una serie de rótulos sincronizados temporalmente con el texto original» (2014: 60). Por lo tanto, los sobretítulos nos llevan a la figura del sobretitulador. En principio el traductor traducía el libreto de la obra, mientras que el técnico se ocupaba de ajustar la traducción al sobretitulado y su proyección durante la representación. Hoy en día, el mismo traductor puede cumplir también el papel de técnico y proyectar manualmente durante una pieza un subtítulo tras otro, teniendo el documento con el subtitulado en el ordenador. Para realizarlo correctamente debe participar en los ensayos teatrales, lo que garantizará la sincronización adecuada del pautado temporal del archivo de sobretitulado junto con la representación escénica. Además debería estar pendiente de los cambios introducidos de 
una representación a otra y saber reaccionar en el caso de improvisación de los actores durante la obra (Carrillo Darancet, 2014: 60-62). Como nos explica Griesel (2009: 123), el sobretitulador está sentado detrás de los técnicos o detrás del público, y trabaja en tiempo real. Se lo puede comparar con un intérprete, a diferencia de que el sobretitulador trabaja con un material prefabricado de segmentos de la traducción basada en un prototipo del texto de salida.

Tanto en Polonia como en España se facilita el acceso a la obra teatral a las personas con discapacidad sensorial, visual o auditiva. En Polonia la iniciativa se llama Teatr bez barier (Teatro sin barreras), mientras que en España su nombre es Teatro accesible. El Teatro sin barreras garantiza los espectáculos con audiodescripción, subtítulos polacos y lengua de signos polaca. El Teatro accesible hace asequible el arte teatral a los discapacitados sensoriales a través del subtitulado, la audiodescripción, los sistemas de inducción magnética y la lengua de signos.

Además, en España funciona el sistema UC3Mtitling, desarrollado por el Instituto Pedro Juan de Lastanosa de la Universidad Carlos III de Madrid junto con el Centro Español de Subtitulado y Audiodescripción, que permite transmitir en directo a través de smartphones y tabletas los subtítulos, audio para la audiodescripción y vídeo para el lenguaje de signos, a base de los elementos de accesibilidad antes preparados gracias a Voz por protocolo de internet (conjunto de recursos que posibilitan que la señal de voz viaje por internet). El sistema fue lanzado el 15 de marzo de 2011 en el Teatro María Guerrero de Madrid (Universidad Carlos III de Madrid).

\section{Entre nosotros, todo va bien, de Dorota Masłowska en su traducción escénica al español}

Ahora pasamos a la parte analítica de nuestro artículo en la que examinamos la versión teatral que Grzegorz Jarzyna realizó en 2009 de la pieza Między nami dobrze jest, de Dorota Masłowska del año 2008 y su traducción al español Entre nosotros, todo va bien, de Xavier Farré, estrenada en la escena madrileña del Teatro Valle-Inclán el 4 de noviembre de 2011.

La pieza fue representada en polaco con los sobretítulos en castellano. Esta información se indicaba en el programa de la pieza y en el material que promocionaba la representación, la cual fue una coproducción de TR Warszawa y Schaubühneam Lehniner Platzen cooperación con el programa Varsovia Capital Europea de la Cultura 2016. Los intérpretes fueron: 
Aleksandra Popławska (La Pequeña Chica Metal), Danuta Szaflarska (La viejecita abatida en una silla de ruedas), Magdalena Kuta (Halina), Maria Maj (Bożena), Adam Woronowicz (Director), Rafał Maćkowiak (Actor), Agnieszka Podsiadlik (Presentadora), Roma Gąsiorowska (Edyta), Katarzyna Warnke (Monika), Lech Łotocki (Presentador). La pieza fue estrenada en el Teatr Rozmaitości en Varsovia el 5 de abril de 2009. El preestreno tuvo lugar en Schaubühne am Lehniner Platz en Berlín el 26 de marzo del año 2009.

La traducción de este texto nació del «fértil» diálogo entre el director Grzegorz Jarzyna y su traductor Xavier Farré. Tal como comenta el mismo traductor, este asistía a las pruebas y ensayos de la pieza para producir un texto donde las palabras surgieran de la forma más natural y propicia para la escena. Por entonces, la pieza teatral no había sido publicada; la versión de la que disponemos nos la proporcionó el propio traductor ${ }^{1}$ de la obra. Tal como rezaba Georges Mounin «Una traducción teatral escenificable es el producto, no de un acto lingüístico, sino de un acto dramatúrgico - de otra manera, como ha dicho Mérimée acerca de la traducción de Révizor, 'uno bien podría traducir el lenguaje, sin traducir la obra'» (1963: 14). Por eso mismo Farré creó una versión prototípica que durante los ensayos teatrales sufrió algunas modificaciones a causa del desarrollo de la puesta en escena, en la que, por ejemplo, se introdujeron elementos adicionales que acentuaron la progresión dramática del texto. En consecuencia, el traductor realizó, además, un trabajo que podemos calificar de dramatúrgico.

Los cambios que sufrió la obra de Masłowska al traducirla al español se deben principalmente al traslado de la pieza a la escena bajo los sobretítulos y la transferencia de los culturemas. Tal como indica Rocío de Frutos (2011: 6-7), la introducción de los sobretítulos en el teatro ha modificado considerablemente los usos interpretativos y las expectativas del público al que se otorga el derecho a comprender sin falta todo el mensaje lingüístico, lo que nos lleva a considerables simplificaciones. A ello podemos añadir la condensación que resulta directamente de la longitud de la pantalla proyectada, la velocidad lectora del receptor y el intento de la restricción mínima posible del hecho presentado en el escenario. Todas estas limitaciones llevaron inevitablemente a una condensación y simplificación que empobrecieron de buen grado la obra teatral de Masłowska en su versión española al perder una parte de los dobles sentidos, juegos de palabras, ambigüedades, lenguaje coloquial,

${ }^{1}$ La autora del artículo quiere dar gracias a Xavier Farré por facilitar la versión de la pieza de Masłowska de Grzegorz Jarzyna y su propia traducción de la pieza al español. 
juerga, errores intencionales, referencias culturales, etc., lo que vamos a ver más en detalle en las partes siguientes del texto.

La puesta en escena, además de la forma de los sobretítulos, forzó a un dialogismo más complejo y desarrollado, lo que podemos observar, por ejemplo, en la agregación de las preguntas de la presentadora que entabla una conversación con el actor y en la división de los parlamentos más largos en las oraciones simples. También en la pieza de Masłowska se añadió un vídeo que presentaba la Varsovia de la época de preguerra. Tal como dice Patrice Pavis (1991: 47) en su artículo «Problemas de la traducción para la escena: interculturalismo y teatro posmoderno», la economía del lenguaje del texto dramático y por ende también del lenguaje de su traducción para la puesta en escena se complementan de forma natural con «todo tipo de medios auditivos, mímicos, gestuales y posturales», acercando el público a la cultura de salida y ayudando en la recepción correcta de la obra.

Según el crítico y dramaturgo teatral Enrique Llovet(1988:12), convertir un texto creado en una lengua, para los espectadores de esa lengua, en un texto para otra nacionalidad implica inevitablemente la adaptación a través de las equivalencias, ritmos, modos, formas y compensaciones, al modo de intentar obtener efectos similares a los producidos por el original. Por su parte, Patrice Pavis (1991: 55-56) habla de diferentes actitudes hacia la cultura en la traducción teatral: 1. Quedarse del lado de la cultura origen, lo que puede causar la incomprensión y reducción del público a los especialistas, 2. Adaptar la cultura origen a la cultura meta que puede traicionar una actitud condescendiente hacia el texto y cultura de origen, 3. Llegar a una transacción entre ambas culturas origen y meta, siendo un término intermedio entre las dos primeras actitudes.

Para analizar la actitud hacia la cultura en la versión española de la pieza de Masłowska nos vamos a basar en la tipología de las técnicas de traducción propuesta por Amparo Hurtado Albir en su manual Enseñar a traducir. Metodología en la formación de traductores e intérpretes (1999).

En la traducción de la pieza de Masłowska aparecen las adaptaciones, donde se reemplaza un elemento cultural polaco por otro propio de la cultura receptora española (Hurtado Albir, 1999: 245), lo que ocurre sobre todo en los títulos de las revistas (Superekspres por El Caso), en los nombres de los establecimientos («Biedronka» por «El Día») y de la comida («ptifury» por «almendrados», «chałwa» por «turrón»). Este tipo de cambios en nuestra opinión no influye en la recepción correcta de la obra.

Contrariamente a las adaptaciones, las generalizaciones, entendidas como el uso de los términos más generales o neutros (Hurtado Albir, 
1999: 247), cambian la recepción de la obra de Masłowska. Enumeremos dos ejemplos: el «familok» (del alemán «Familien-Block», 'tipo de casa para muchas familias para los trabajadores de la industria pesada, principalmente mineros del carbón, construido a finales del siglo XIX y principios del siglo XX en Polonia') traducido por "ciudad minera»; «ciemnogród» (el término apareció en la novela de Stanisław Kostka Potocki de 1820 titulada Podróż do Ciemnogrodu, en la que se critica los juicios conservadores de los partidarios del sistema que prevalecía en la Polonia de pre-partición) por «zafiedad». Estas generalizaciones pueden ocasionar, por ejemplo, la pérdida del lenguaje coloquial («na angola» por «a inglés», «dwie dyszki» por «veinte zlotys», «tych Kaczorów» por «esos Kaczynski») o de la jerga de la ciudad («bumelować» por «no hace el vago», «ktoś zadał komuś bobu» por «se llevará por delante», «hasiok» por «un trozo de porquería»). Como rezan los teóricos de la traducción, por un lado, el traductor debe reflejar en su traducción las variedades lingüísticas diferentes del lenguaje estándar que aparecen en el texto original (Newmark, 1992: 37), y por otro, «debe optar necesariamente entre cierta pérdida de coloquialidad o el uso de un criterio comunicativo que le permita reflejar más libremente las expresiones de este tipo» (Pérez, 2003: 42).

Si se trata de la traducción de los juegos de palabras, nos basamos en el artículo de Dirk Delabastita (2004: 600-606) titulado «Wordplay as a translation problem: A linguistic perspective», en el que el autor enumera diferentes estrategias para traducir los juegos de palabras. En el caso de «niepokój», basado en la polisemia y entendido como inquietud y falta de la habitación traducido por «no habitación», hablamos de la traducción del juego de palabras por otra expresión que no es un juego de palabras (pun $\rightarrow$ non-pun), ya que el traductor mantiene, de los dos, un sentido de la palabra, perdiendo el otro (2004: 604). Por su parte, las expresiones "chleba, chleba coś słyszałam o jakimś chlebaku» traducida como «pan, pan, algo he oído de una panacea», y «obóz kon-dycyjny», que sugiere también un campo de concentración (obóz koncentracyjny) por «campo de con-densación» entrarían en la categoría de traducir el juego de palabras de la lengua original por un juego de palabras de la lengua meta (pun $\rightarrow$ pun) (2004: 604).

Igualmente, algunos errores intencionales se perdieron en la traducción: «A co to jest 'chleba'» (chleb en nominativo) por falta de declinación en español se tradujo como "¿Y qué es eso del pan?», mientras que «komputerowe symulacje hołd» se tradujo al español con la construcción gramatical correcta «héroes de juegos de ordenador». No obstante, otros errores intencionales sí se pudieron conservar: 
«kurturalny» por «curtural» o «wieża Eiffli» por «Torre Feller». La ortografía fonética de las palabras polacas, esto es, tal y como se las pronuncia en la lengua polaca tampoco se pudo mantener, empleándose en estos casos en castellano la ortografía según la norma académica española, por ejemplo, «(z) Kerfura», en español «Carrefour». Todas esas pérdidas se deben principalmente a la condensación de los sobretítulos y a la inmediatez del hecho escénico y, por ende, a la inmediatez de su percepción y recepción. Como indica Sara Ramos (2012: 219) en su artículo titulado "Quando o palco e a página se encontram na tradução»: «o espectador de uma represenção teatral estará sempre confinado a um momento e um local específicos e irrepetíveis [...] É um momento único de produção de significado que jamais se repetirá». Tenemos que subrayar que, aunque la lectura del libro no se rige por la inmediatez, en el sentido de que el lector puede modificar su ritmo, volver para atrás, consultar las dudas en el diccionario, etc., tampoco en la traducción de otra obra de Masłowska, la novela Wojna polsko-ruska pod flaga biało-czerwona (Blanco nieve, rojo Rusia), se pudo conservar todos los elementos culturales y locales, las referencias históricas o los errores intencionales, siendo esa novela igualmente una obra completamente impregnada por la cultura polaca. La traductora de esta novela al español, Joanna Orzechowska, comenta que a la hora de traducirla buscó un registro intermedio para que el texto sea comprensible y que, en primer lugar, pensó en el lector y en si el resultado era legible o requería una nota del traductor. También como Farré optó por la simplificación, sacrificando algunos matices del texto original, por ejemplo las incorrecciones gramaticales que en español no serían comprendidas (J. Orzechowska, comunicación personal, 20 de noviembre de 2012).

Cieślik (2012, en línea) recoge unas clarificadoras declaraciones de Masłowska «Vivo en este país y él cada día sobrepasa mis pensamientos con toda su carga histórica. Polonia me sobrelleva tanto a mí como a lo que escribo». Por ello, la pieza está llena de alusiones relativas a Polonia, su historia, sociedad: referencias a la cultura polaca simbólica. Por desgracia, algunos de esos elementos no pueden ser entendidos por los espectadores hispanohablantes: por ejemplo, el monólogo de radio basado en la retórica de Radio Maryja, a pesar de mantenerse, no produce la connotación adecuada. Perdemos asimismo la lengua de los salones de Varsovia antes de la guerra, de Antoni Słonimski, Julian Tuwim, etc.; la lengua de las bellas viejas formas («brukając» por «ensuciaban») que aniquiló la guerra, lo que caracteriza el habla de una viejecita. La pérdida se refiere también al mito de la guerra y de la Varsovia antes de la guerra, evocados ambos a través de los recuerdos de la abuela. Los personajes de 
Masłowska se avergüenzan de su estatus social y sufren con su propia identidad después de la transformación capitalista y la entrada a la Unión Europea. Como podemos observar, las pérdidas entonces son ineludibles en el caso de la traducción de la pieza teatral en la que la autora se pregunta por «nosotros», por la identidad polaca, por la relación de los polacos con su carácter polaco, creando el retrato de la identidad negativa. Incluso la misma autora de la pieza ya afirmaba en una entrevista que su obra en cierto nivel era absolutamente intraducible y sólo se podía traducir el grueso del texto (Sobolewska, 2007).

\section{A modo de conclusión}

Hablando en los términos de Pavis, podemos decir que Xavier Farré, traductor de la pieza Entre nosotros, todo va bien de Dorota Masłowska, logra llegar en su traducción a una transacción entre la cultura polaca y española, de tal forma que ambas culturas se comunican en el sentido de «vasos comunicantes» (Pavis, 1991: 56), aunque tiene que topar inevitablemente con un doble problema. Por un lado, la traducción literaria se ve impregnada de distintos rasgos que efectivamente involucran a la cultura polaca, tales como las formas de expresión, una descripción «cultural» del país y de lo que se puede considerar polaco en la lengua extranjera. Por otro lado, las formas de traducción escénica que deben aparecer como sobretítulos, por razones técnicas, restringen todavía más su tarea. De esta manera, le imponen al traductor la brevedad, la concisión y la máxima condensación de ideas, reduciendo así el espacio de acción para la traducción. El teatro en su hecho puramente escénico marca restricciones que no aparecerían en caso de que la traducción fuese única y meramente literaria. Volviendo a Pavis (1991: 60-61) «la traducción para la escena hace préstamos distintos a los de una traducción puramente lingüística, y que tiene lugar una traducción real en el nivel de la puesta en escena como un todo».

\section{Bibliografía}

BBC, (Gran Bretaña 2009). «Theater performances available in eight languages» [en línea] <http://news.bbc.co.uk/2/hi/technology/8380266.stm>, fecha de consulta: 10 de marzo de 2018. 
BLIKONT, K. et al. (2014). «Tłumacz w teatrze», Didaskalia, 124, 130-140.

CARRILLO DARANCET, J. M. (2014). Del original al sobretitulado: la adaptación y la traducción audiovisual en el teatro contemporáneo, tesis doctoral inédita. Madrid: Universidad Complutense de Madrid.

CIEŚLIK, M. (Polonia 2012). «Dlaczego nie mam myśleć Rymkiewiczem» [en línea] $<$ http://archiwum.rp.pl/artykul/1167528-Dlaczego-nie-mam-myslec-Rymkiewiczem.html>, fecha de consulta: 30 de marzo de 2018.

DELABASTITA, D. (2004). «Wordplay as a translation problem: A linguistic perspective», en H. KITTEL., A. P. FRANK, N. GREINER, T. HERMANS, W. KOLLER, J. LAMBERT y F. PAUL (eds.), Übersetzung, Translation, Traduction. Berlin, New York: Walter de Gruyter, 600-606.

EATOCK, C. (Canadá 2003). «COC celebrates its surtitle revolution» [en línea] $<$ http://www.theglobeandmail.com/arts/coc-celebrates-its-surtitle-revolution/article1009862>, fecha de consulta: 10 de marzo de 2018.

EZPELETA PIORNO, P. (2007). Teatro y traducción. Aproximación interdisciplinaria desde la obra de Shakespeare. Madrid: Cátedra.

FRUTOS, R. de (España 2011). «Los sobretítulos como herramienta de comunicación en la ópera actual» [en línea] <http://www.comunicacion21.com/wpcontent/PDF/Sobretitulos.pdf>, fecha de consulta: 30 de marzo de 2018.

GAMBIER, Y. (2004). «La traduction audiovisuelle: un genre en expansion», Meta: journal des traducteurs/Meta: Translators' Journal, 49/1, 1-11.

GRIESEL, Y. (2009). «Surtitling: Surtitles another hybrid on a hybrid stage», Trans. Revista de Traductología, 13, 119-127.

HURTADO ALBIR, A. (1999). Enseñar a traducir. Metodología en la formación de traductores e intérpretes. Madrid: Edelsa.

LINDSAY, J. (ed.) (2007). Between Tongues: Translation and / of / in Performance in Asia. Singapore: NUS Press.

LLOVET, E. (1988). «Adaptaciones teatrales», Boletín Informativo de la Fundación Juan March, 180, 3-16.

MARTÍNEZ SIERRA, J. J. (coord.) (2012). Reflexiones sobre la traducción audiovisual: Tres aspectos, tres momentos. Valencia: Universidad de Valencia.

MASŁOWSKA, D. (2008). Między nami dobrze jest. Warszawa: Lampa i Iskra Boża.

MASŁOWSKA, D. (2011). Entre nosotros, todo va bien, obra inédita (trad. X. FARRÉ).

MOUNIN, G. (1963). Problèmes théoriques de la traduction. Paris: Gallimard.

NEWMARK, P. (1992). Manual de traducción. Madrid: Cátedra.

PAVIS, P. (1991). «Problemas de la traducción para la escena: interculturalismo y teatro posmoderno», en H. SCOLNICOV y P. HOLLAND (comp.), La obra de teatro fuera de contexto. El traslado de obras de una cultura a otra. México, D.F.: Siglo Veintiuno Editores, 39-62.

PÉREZ, N. (2003). «Panorama de la narrativa española del siglo XX publicada en Italia: algunas conclusiones», Tradurre dallo spagnolo. Giornata di studio e confronto, 35-45.

RAMOS, S. (2012). «Quando o palco e a página se encontram na tradução», en M. CARVALHO y D. DI PASQUALE (org.), Depois do labirinto: Teatro e tradução. Lisboa: Nova, 213-250. 
SOBOLEWSKA, J. (Polonia 2007). «Masłowska: nie jestem poprawna politycznie» [en línea] <http://web.archive.org/web/20100317024256>, <http://www. dziennik.pl/kultura/ksiazki/article96083/Maslowska_Nie_jestem_poprawna_politycznie.html>, fecha de consulta: 30 de marzo de 2018.

TOMASZKIEWICZ, T. (2006). Przekład audiowizualny. Poznań: UAM.

UNIVERSIDAD CARLOS III DE MADRID (España 2011). «El Centro Dramático Español hace accesible el teatro a las personas sordas gracias al CESyA y al UC3MTITLING, tecnología desarrollada por la UC3M» [en línea] <http:// portal.uc3m.es/portal/page/portal/investigacion/parque_cientifico/actualidad_agenda/not_CIT_CesyaCDN_11mzo>, fecha de consulta: 12 de marzo de 2018. 